\title{
Sobredeterminação socioecológica da saúde da ruralidade em Humaitá, AM, Brasil
}

\author{
Socio-ecological super-determination of health in rural areas \\ in Humaitá, State of Amazonas, Brazil
}

Gabriel Eduardo Schütz ${ }^{1}$

Marcia Gomide da Silva Mello ${ }^{1}$

Marcia Aparecida Ribeiro de Carvalho ${ }^{1}$

Volney de Magalhães Câmara ${ }^{1}$

${ }^{1}$ Instituto de Estudos em Saúde Coletiva, Universidade Federal do

Rio de Janeiro. Av. Horácio Macedo S/N, Cidade

Universitária. 21.944-970

Rio de Janeiro RJ Brasil.

gabriel@iesc.ufrj.br

\begin{abstract}
The scope of this article is to apply a trans-disciplinary socio-ecological approach to discuss the super-determination of health in rural areas of the southern Amazon region from a case study developed in Humaitá in the State of Amazonas in Brazil. Field data were collected using ethnographic techniques applied during three expeditions in Humaitá's rural area between 2012 and 2014. Based on the 'socio-ecological metabolism' analytical category, a descriptive and theoretical analysis of four crucial components in the process of super-determination of local health are presented: (1) the composition of the local rural population; (2) fixed and changing territorial aspects; (3) construction of socio-ecological identities; (4) ethnic conflict between Indians and non-Indians. The conclusion reached is that the incorporation of a socio-ecological approach in territorial-based health research provides input for analyses of the local health situation through the systematization of information related to the process of super-determination of health. It also helps in the construction of trans-disciplinarity, which is a necessary epistemological condition for addressing the complex reality at the interfaces of social production, the environment and health.

Key words Environmental health, State of Amazonas, Rural areas, Health determinants
\end{abstract}

Resumo Este artigo tem como objetivo aplicar uma abordagem socioecológica transdisciplinar para discutir a sobredeterminação da saúde da ruralidade sul-amazônica, a partir de um estudo de caso desenvolvido em Humaitá, AM, Brasil. Os dados de campo foram coletados por meio de técnicas etnográficas aplicadas no decorrer de três expedições realizadas na área rural do município, entre 2012 e 2014. Apresenta-se uma análise descritiva e teórica, baseada na categoria analítica 'metabolismo socioecológico', de quatro componentes cruciais no processo de sobredeterminação da saúde local: (1) a conformação da população rural local; (2) os fixos e os fluxos territoriais; (3) a construção das identidades socioecológicas; (4) o conflito étnico entre indios e não indios. Concluise que incorporação de estudos socioecológicos em pesquisas de saúde de base territorial permite dar subsídios às análises de situação de saúde local por meio da sistematização de informações relacionadas com os processos de sobredeterminação da saúde. Também permite avançar no sentido da transdisciplinaridade, uma condição epistemológica necessária para a abordagem de uma realidade complexa construída nas interfaces da produção, do ambiente e da saúde.

Palavras-chave Saúde ambiental, Amazonas, Ruralidade, Determinantes da saúde 


\section{Introdução}

Os modos de produção localizados em um território determinam, dentre outras relações sociais históricas, a organização do espaço geográfico; o regime de apropriação dos recursos e compartimentos ambientais; o regime de trocas materiais e simbólicas e; consequentemente, os processos de subjetivação por meio dos quais são construídas as identidades. Todos estes elementos contribuem a determinar - em forma direta ou indireta - as condições de saúde da população que habita esse território e é sujeito dos processos produtivos em sua dualidade gerador/consumidor. Neste sentido, os modos de produção, ou seja, as formas de gerar, transportar, distribuir e consumir mercadorias, sobredeterminam os demais processos de determinação da saúde em diferentes níveis de agregação espacial.

Em outras palavras, as possibilidades de uma boa qualidade de condições de vida de uma população - entendida como conceito ampliado de saúde - está condicionada por determinantes sociais históricos determinados, a priori, pelos modos de produção dos quais é sujeito/está sujeita. Desta forma, com maior ou menor sensibilidade, mudanças nas formas de produzir acabam se expressando em mudanças nos perfis de morbidade/mortalidade; de qualidade de vida e de conflitividade social.

Neste artigo apresentam-se os resultados de um estudo de caso desenvolvido no município de Humaitá (AM), localizado na bacia do rio Madeira, no sul do estado do Amazonas, na fronteira com o estado de Rondônia. Grande parte dos seus $33 \mathrm{mil} \mathrm{Km}^{2}$ - uma superfície maior que a do estado de Alagoas - ainda é coberta pela Floresta Amazônica, embora na atualidade seja muito difícil afirmar que, na qualidade de ecossistema, ainda mantenha a sua composição biótica e abiótica original em função das intensas modificações no uso do solo introduzidas por colonizadores e imigrantes ao longo dos séculos; modificações que continuam a acontecer na forma de novas modalidades, mais intensas e mais mediadas pela tecnologia.

O objetivo traçado para este estudo foi o de aplicar uma abordagem socioecológica transdisciplinar para discutir a sobredeterminação da saúde de uma população rural amazônica. Para isto, irá descrever e analisar os modos de produção que definem tanto as relações materiais com o território quanto as identidades socioecológicas mais visíveis no território abordado.

A principal categoria analítica utilizada, transversal ao longo do trabalho, é o 'metabolis- mo socioecológico' (MSE). Esta categoria é uma elaboração neomarxista do conceito de 'metabolismo social', pertencente à 'Teoria da renda do solo' de Karl Marx ${ }^{1}$.

Por meio desta teoria Marx explica, entre outras questões, a insustentabilidade dos fluxos rural-urbano-rural em termos da degradação da fertilidade do solo; a transformação de riqueza natural (no caso, das terras férteis) em riqueza monetária; e a forma em que o modo de produção capitalista converte diferenças naturais em diferenças sociais ${ }^{2}$.

O conceito de metabolismo social em Marx é recuperado e atualizado por István Mészáros ${ }^{3} \mathrm{e}$ adaptado à análises socioecológicas de base materialista histórica, por autores do Marxismo Ecológico como Brett Clark e John Bellamy Foster ${ }^{4}$.

Poder-se-ia dizer que o MSE pretende dar conta da análise crítica das relações sociais que se estabelecem entre o modo de produção capitalista e as condições territoriais de produção nas sociedades contemporâneas, em que a construção de identidades está permeada por uma complexa sinergia de fluxos materiais, simbólicos e de desejos.

A proposta inédita deste artigo é utilizar o conceito de MSE como ferramenta para abordar, em forma sistemática e transdisciplinar, a sobredeterminação da saúde de populações localizadas e, por este caminho, contribuir às análises de situação de saúde de base territorial.

O objeto de estudo desta pesquisa é, portanto, o processo de sobredeterminação socioecológica da saúde da ruralidade em um município do sul do Amazonas; ou dito em forma mais genérica, é a forma em que as relações materiais de produção - historicamente e ecologicamente condicionadas - sobredeterminam o processo saúde-doença de coletivos sociais localizados.

\section{Metodologia}

A pesquisa de campo foi realizada durante três expedições (novembro de 2012; fevereiro de 2014 e maio de 2014), no marco das atividades de pesquisa do Instituto Nacional de Pesquisa Translacional em Saúde e Ambiente na Região Amazônica (INPeTAm).

Os dados de campo foram coletados por meio de um estudo etnográfico, aplicado para identificar os elementos constituintes do processo metabólico socioecológico local que poderiam ser considerados sobredeterminantes da saúde da ruralidade no Sul do Amazonas. 
O MSE, como objeto de estudo, se inscreve no âmbito teórico da Economia Política, mais particularmente, das relações materiais que os coletivos sociais estabelecem com o espaço geográfico em que desenvolvem suas vidas e constroem suas identidades. Em estudos deste tipo, a aplicação do método etnográfico não busca conhecer aspectos culturais singulares de uma comunidade localizada, mas compreender os nexos que a encadeiam nos sistemas de trocas locais, regionais e até os globais ${ }^{5}$.

Neste sentido, foram aplicadas duas técnicas etnográficas para a coleta dos dados de campo: (i) observação, entendida como o ato de perceber as atividades e inter-relações territoriais; e (ii) análise de materiais de arquivo, mais especificamente, de fontes de dados oficiais secundários, bem como de produções acadêmicas. Para Angrosino $^{5}$, a observação; a análise de material de arquivos, e realização de entrevistas constituem as três técnicas principais da coleta de dados etnográfica. No caso específico deste estudo, a realização de entrevistas não foi considerada necessária para cumprir com o objetivo traçado.

A observação foi realizada por meio de um registro do cenário de campo em busca de padrões (históricos, geográficos e econômicos) que permitissem caracterizar os modos de produção que definem as identidades socioecológicas locais. A partir desses dados, recorreu-se à análise de material de arquivo para o aprofundamento dos aspectos mais relevantes na análise descritiva e teórica da relação entre os modos de produção locais e a sobredeterminação da saúde dos coletivos que conformam as diferentes identidades socioecológicas.

A partir das observações registradas nas expedições, quatro componentes do processo de sobredeterminação da saúde local foram considerados cruciais: (1) o processo de conformação da miscigenada população rural tradicional da bacia do rio Madeira; (2) o conjunto dos fixos e dos fluxos territoriais que relacionam os recursos ecossistêmicos com os modos de produção; (3) a construção das identidades socioecológicas determinadas a partir das relações materiais estabelecidas pelos coletivos rurais; (4) o conflito étnico entre índios e não índios, recentemente visibilizado através de episódios de violência no município.

O percurso metodológico para a análise transdisciplinar destes quatro pontos contempla: (i) uma reconstrução de processos históricos remotos e recentes, elaborado a partir da leitura de autores locais; (ii) a caracterização do espa- ço geográfico por meio das categorias de fixos e fluxos territoriais definidos por Milton Santos ${ }^{6}$; (iii) a caracterização de tipos ideais da população rural local amazônica, aplicando a ferramenta concebida originalmente por Max Weber ${ }^{7}$, que permite selecionar um conjunto de caraterísticas empíricas que fazem inteligíveis uma determinada abstração (neste caso, identidades socioecológicas) dentre outras possíveis; e (iv) uma análise da conflitividade étnica envolvendo os povos indígenas da região elaborada a partir do conceito lacaniano de Foraclusão ${ }^{8}$.

\section{Resultados e discussão}

\section{A formação histórica do "campesinato amazônida"}

$\mathrm{Na}$ sua dimensão humana, a bacia do rio Madeira já estava habitada por povos indígenas quando, a partir de 1640, começou a colonização europeia com as primeiras expedições e a posterior instalação de missões jesuítas. Na realidade, desde o século XVI, espanhóis e holandeses já vinham circulando pelo rio Madeira em viagens de reconhecimento territorial, mas não fundaram assentamentos coloniais ${ }^{9}$.

No final do século XIX, o primeiro ciclo da borracha (1879 a 1912) atraiu trabalhadores rurais, principalmente chegados desde os estados do Maranhão e do Ceará ${ }^{10}$. Mais tarde, na primeira década do século XX, novos imigrantes chegaram na região para trabalhar na construção da Estrada de Ferro Madeira-Mamoré. Na década de 1940 houve uma nova corrente migratória, desta vez, composta por grupos familiares expulsos do sertão nordestino pela grande seca que flagelava aquela região. Aos poucos, as famílias foram entrando na floresta, estabelecendo-se em pequenas comunidades ribeirinhas à beira de rios e lagos, e, misturando-se com os antigos habitantes da floresta $^{11}$, gerando a miscigenação que atualmente caracteriza o coletivo social chamado de "campesinato amazônida”, por autores como Lourdes Gonçalves Furtado ${ }^{12}$.

A partir da década de 1970, os processos migratórios perderam seu caráter "espontâneo" e passaram a ser oficialmente promovidos pela ditadura cívico-militar governante, cuja estratégia geopolítica incluía a ocupação planejada de uma região que considerava "esvaziada". $\mathrm{Na}$ época, facilitou-se o assentamento de famílias rurais sulistas; quer dizer, de coletivos sociais portadores de outras tradições culturais. De acordo com Cor- 
rea $^{10}$, estes processos têm causado estranhamentos nos regimes de troca, impondo a necessidade de adaptações, tanto por parte dos recém chegados quanto dos anteriores habitantes da floresta.

O mosaico étnico-cultural presente no território, por um lado, favoreceu os processos de miscigenação da população local e, por outro lado, contribuiu com os processos de construção de identidades coletivas na ruralidade amazônica junto com as diferentes formas históricas de apropriação e exploração dos recursos territoriais.

\section{Caracterização dos fixos e fluxos territoriais na bacia do rio Madeira}

Poder-se-ia dizer que os principais fluxos metabólicos socioecológicos atuais na bacia do rio Madeira estão condicionados, basicamente, por dois fixos territoriais em particular: (i) as caraterísticas morfométricas e hidrológicas da região, e (ii) as características do sistema rodoviário enquanto capacidade técnica instalada.

A paisagem local é constituída por um mosaico de terrenos altos e baixos segmentado por rios, lagos, igapós (pântanos nas matas) e igarapés (estreitos fluxos d'água que separam ilhas de terra firme). As áreas baixas, ou várzeas, são terras sujeitas a inundações sazonais. As várzeas são exploradas em todos seus ciclos estacionais mediante os modos de produção tradicional praticadas por ribeirinhos, indígenas, e pequenos agricultores familiares. Os terrenos mais altos dificilmente alagam nas cheias estacionais. Tradicionalmente exploradas na base da agricultura familiar por populações caboclas, estas terras são as mais visadas por parte de ruralistas que defendem a ampliação da fronteira agropecuária do agronegócio.

Por sua vez, os cursos d'água constituem vias de circulação de matéria biótica e abiótica fundamentais (às vezes, as únicas disponíveis), inclusive, para a comunicação e o transporte entre assentamentos humanos. O rio Madeira, por exemplo, é uma hidrovia estratégica fundamental, uma das mais importantes do Brasil para o escoamento da produção agrícola produzida em Rondônia, Mato Grosso e no sul do Amazonas ${ }^{13}$, sobretudo, de soja transgênica exportável.

Numa região mediterrânea com enorme potencial produtivo, a capacidade aquaviária do rio Madeira, junto com o traçado estratégico de rodovias federais, há décadas vêm facilitando a ampliação da fronteira econômica no sul-leste da Amazônia Legal.

A paisagem do município de Humaitá está segmentada também por duas rodovias federais: uma diagonal, a BR-319, que une as cidades de Manaus (AM) e Porto Velho (RO); e uma transversal, a BR-230 (Transamazônica) que atravessa sete estados das regiões Norte e Nordeste, desde Lábrea (AM) até o porto atlântico de Cabedelo na Paraíba. Embora não passe pelo município, também exerce forte influência regional a BR364 , importante rodovia diagonal que se inicia no município paulista de Limeira, atravessa parte de Minas Gerais, Goiás, Mato Grosso, Rondônia até chegar no município de Rodrigues Alves, no Acre, no extremo oeste do Brasil. Apesar das condições precárias em que se encontram as rodovias amazônicas (em longos trajetos ainda há estrada de terra), seu mero traçado tem facilitado a expansão da fronteira agropecuária nos seus entornos desmatados.

Nas últimas décadas, a evolução do Produto Interno Bruto (PIB) brasileiro vem mostrando uma forte tendência à terceirização da economia nacional ${ }^{14}$. No entanto, a matriz produtiva que impulsiona a economia amazonense (e da qual depende seu setor terciário) continua a ser a produção primária (agricultura, pecuária, mineração, exploração madeireira dentre outras). Neste contexto, poder-se-ia afirmar que, se as particularidades do ecossistema amazônico definem os tipos de atividades econômicas a serem praticadas, são suas características climáticas as que condicionam fortemente sua dinâmica de execução. Em efeito, o ecossistema amazônico tem clima equatorial, quente e úmido, com duas estações pluviais: uma chuvosa (de outubro a abril) e uma de estiagem (de maio a setembro). Isto determina um regime fluvial (enchente, cheia, vazante e seca) que define (a) o planejamento das atividades (calendário agrícola), em especial nas várzeas; e (b) a maior ou menor facilidade do escoamento da produção, em vista da frágil capacidade técnica instalada na Região Norte para o transporte em grande escala. Resumindo: o ciclo da economia primária na Amazônia (produção, transporte, distribuição e consumo de valores de troca com pouco ou nenhum beneficiamento) depende da incidência de chuvas e dos níveis de flutuação dos rios, cujo nível pode crescer até interromper temporariamente a circulação rodoviária.

Por outra parte, é válido pensar que os fluxos territoriais de produtos e mercadorias (e, por conseguinte, de dinheiro) venham associados a fluxos migratórios humanos atraídos pela possibilidade de obter parte dessa riqueza circulante. Neste sentido, é provável que a percepção social de um novo horizonte de "prosperidade" em um território considerado pouco explorado pelas 
forças do "progresso" seja um dos fatores que expliquem a explosão demográfica no município de Humaitá nas últimas décadas.

No período entre os dois últimos censos demográficos, a população do município se incrementou em $34,52 \%$, um aumento considerável, considerando que a população do Estado do Amazonas cresceu apenas 2,15\%; e a do Brasil, $1,7 \%{ }^{15}$. Nesse mesmo período, 48 dos 62 municípios amazonenses registraram encolhimento da população rural em índices que chegam a $40,25 \%$, enquanto que a população rural de $\mathrm{Hu}$ maitá aumentava um $4,07 \%{ }^{16}$. Ainda segundo o censo demográfico 2010, apenas $69 \%$ dos 44.116 habitantes de Humaitá são moradores da área urbana, e tanto a população urbana quanto a rural apresenta clara maioria de homens ${ }^{17}$. Em outras palavras, trata-se de um município com população rural e masculina sensivelmente maior que a média brasileira.

\section{A determinação socioecológica das identidades coletivas na ruralidade no sul do Amazonas}

Rios e rodovias - enquanto canais privilegiados de fluxos de matéria, energia e informação - definem e distinguem os espaços da ruralidade amazônica, ao menos, na perspectiva dos modos dominantes de produção em cada um desses espaços. Sendo esses espaços importantes fatores determinantes da construção coletiva das identidades rurais na região, ao menos, na forma em que essas comunidades são reconhecidas pelo poder público do município. Neste sentido, haveria uma população rural "ribeirinha", que habita às margens de hidrovias e corpos d'água; e uma população rural "das Brs", assentada nos entornos e proximidades das rodovias.

Em termos de metabolismo socioecológico, trata-se de coletivos sociais cujo tipo ideal é completamente diferenciado. Isto é, distinguem-se nos modos de produção e nas relações de trocas que são capazes de estabelecer.

O tipo ideal da população rural ribeirinha humaitaense explora as várzeas e os corpos d'água, dedicando-se à pesca e ao extrativismo artesanais, bem como a agricultura familiar em forma condicionada pelo regime pluvial e fluvial. Tal como apontou Maria Terezinha Corrêa ${ }^{10}$, durante as cheias, os ribeirinhos da bacia do rio Madeira dedicam-se preferentemente à pesca $\mathrm{e}$ ao extrativismo, mormente da castanha e eventualmente diversifica sua renda com a extração dos óleos de copaíba e das sementes de andiroba; da coleta de açaí, do tucumã e de outras frutas da estação. Na época da seca, o ribeirinho prioriza a produção de farinha d'água, a partir da mandioca brava. Grande parte dos produtos do ribeirinho tem valor de uso, sendo consumidos na própria comunidade; já os excedentes costumam ser comercializados como valores de troca na cidade de Humaitá, ou seja, também são consumidos no próprio território.

Os ribeirinhos, em geral, são frequentemente incluídos na categoria ambientalista "povos das águas" e, portanto, diferenciados da categoria "povos da floresta" referida à população rural amazônica dedicada ao extrativismo florestal artesanal tais como castanheiros e seringueiros ${ }^{18}$.

Cabe destacar que os ribeirinhos, abstraídos como "povo das águas", não se reduzem apenas ao "beiradeio" amazônico, mas também a outras comunidades tradicionais, tais como as populações caiçaras, caranguejeiros de mangues, pescadores artesanais de baias, de rios e pantanais em todo o Brasil. Em princípio, os povos das águas dependeriam mais da integridade ecológica do compartimento ambiental aquático, sendo mais associado à pesca; ao tempo em que os povos das florestas dependeriam mais da integralidade do compartimento ambiental florestal.

Estas categorias formam parte de um conjunto de quatro, que incluem também os "povos do campo" e os "povos das cidades". No entanto, na ocasião dos preparativos da $1^{\text {a }}$ Conferência Nacional de Saúde Ambiental, que foi realizada de 9 a 12 dezembro de 2009, em Brasília (DF), as instituições parceiras desenvolveram Seminários Temáticos focados nas problemáticas dos Povos das Florestas (Belém-PA, 19 a 20 de agosto de 2009), dos Povos do Campo (Cuiabá-MT, de 17 a 18 de setembro de 2009), e dos Povos das Cidades (Guarulhos-SP, de 24 e 25 de setembro de 2009). Nessa oportunidade, os ribeirinhos da Amazônia estavam incluídos como "povos das florestas". Embora seja dúbio tentar estabelecer uma eventual distinção antropológica entre a população rural ribeirinha e de Brs quando se trata do "campesinato amazônida" tradicionalmente assentado na região, do ponto de vista da Ecologia Política, a classificação de diferentes "povos", de acordo com o compartimento ambiental que sustenta sua forma de vida, facilita a visualização das relações de poder antagônicas na apropriação e usufruto dos recursos territoriais, quer dizer, na caracterização dos cenários de disputa e dos atores sociais envolvidos em conflitos ambientais.

Nesta perspectiva, não é possível estabelecer um único tipo ideal para a população rural das 
BRs no município de Humaitá. Um dos possíveis tipos é caracterizado pelo tradicional "caboclo" amazônico assentado em terras firmes, menos sujeitas aos alagamentos estacionais, onde pratica atividades agropecuárias, madeireiras e de extrativismo florestal na base artesanal da agricultura familiar. Este tipo de camponês amazônida comporia a categoria "Povos da Floresta", quando sua produtividade depende do ecossistema amazônico propriamente dito, ou a categoria "Povos do campo", quando vende sua força de trabalho aos fazendeiros que exploram áreas rurais desmatadas, nas quais a floresta amazônica foi transformada em savanas de pastagem ou em extensas planícies de monoculturas. Precisamente, esse é o outro tipo possível nas BRs: o ruralista mormente de origem não amazônica, que não hierarquiza formas tradicionais de produção agropecuária ou florestal, mas a utilização de recursos tecnológicos que lhe permitem produzir em larga escala commodities destinadas ao consumo em mercados extraterritoriais, tais como grãos de soja, madeiras da floresta ou de eucalipto e carne bobina.

A diferença das formas tradicionais de produção rural amazônica, esta forma de produção rural (modalidade vulgarmente chamada de "agronegócio") promove ao menos quatro grandes transformações no metabolismo socioecológico local:

(1) introduz no ecossistema amazônico toneladas de insumos exógenos, tais como fertilizantes químicos; organismos geneticamente modificados; agrotóxicos herbicidas e inseticidas; e maquinaria agrícola à base de combustíveis fósseis, dentre outros;

(2) instala profundas transformações no mundo do trabalho, tanto em relação aos processos de trabalho propriamente ditos, quanto em relação às mudanças nas formas das relações trabalhistas;

(3) em função disto, atrai novos contingentes humanos ao território, que embora os grupos mais privilegiados podem assentar-se em forma devidamente planejada, em geral, a população rural é vulnerada em péssimas condições de habitação, em assentamentos precários e irregulares, tanto na área rural quanto nas periferias urbanas; e finalmente

(4) Promove uma variedade de atividades produtivas de bens e serviços, incrementando a circulação de pessoas, mercadorias e de dinheiro, com as consequentes elevações das taxas metabólicas de (i) consumo material e energético; (ii) geração de resíduos orgânicos e sintéticos em uma região estruturalmente carente nos serviços de saneamento básico, ocasionando a destinação inapropriada de esgotos e de lixo nos solos e nos cursos d'água.

Dito de outra maneira, este modo de produção primária favorece o estabelecimento de fluxos de matéria biótica e abiótica, de energia e de informação marcadamente diferentes (quando não estressantes ou até antagônicos) daqueles fluxos que sustentam os sistemas ecológicos originais, em toda sua complexa (e frágil) diversidade. Vale lembrar que, embora sejam derivadas de processos que respondem a lógicas de determinação diferentes à ruralidade, o ecossistema local também tem sido fortemente impactado de diversas maneiras pelas construções do Complexo Hidrelétrico do Rio Madeira, composto por duas usinas de grande porte: UHE Jirau (3.300 MW) e UHE Santo Antônio (3.150 MW) em Rondônia.

\section{O conflito entre índios e não índios}

O Estado brasileiro, em forma semelhante à maioria dos demais países latino-americanos, tem tido ao longo da história atitudes ambíguas e até contraditórias em relação às diferentes etnias originárias do continente americano, cujas identidades diversas têm sido assimiladas nas categorias equivalências "índio" e "indígena", até o ponto de se transformarem em autorreferenciais.

No seu aspecto inclusivo, o Estado brasileiro, por meio da Constituição Federal reconhece aos povos indígenas suas especificidades étnicas e culturais bem como estabelece seus direitos sociais, sendo principais os artigos 231 e 232 do capítulo VIII (Dos Índios) do Título VIII (Da ordem social). Estes direitos são reafirmados pela Convenção no. 169 da Organização Internacional do Trabalho (OIT), ratificada pelo Brasil em $2003^{19}$. É destacável o fato do país ter instituído uma Política Nacional de Atenção à Saúde dos Povos Indígenas ${ }^{20}$ e uma Política Nacional de Gestão Territorial e Ambiental de Terras Indígenas que, além do reconhecimento das singularidades culturais, postula a proteção territorial e melhoria da qualidade de vida nas terras indígenas ${ }^{21}$.

Todavia, as populações indígenas constituem um Outro que historicamente vem desafiando a capacidade de lidar com a alteridade tanto do poder público quanto da sociedade brasileira "não índia", oscilando entre os extremos da invisibilidade à presença que incomoda, seja por suas demandas ou pelos métodos utilizados para expressar essas demandas.

A contradição índio/não índio é um lugar de perplexidade quando visto na perspectiva da dis- 
tinção entre população rural e urbana; rural ribeirinha e rural de BRs, tal como foi desenvolvida até agora. Provavelmente o caso dos povos indígenas do sul amazônico constituam um caso que expressa a síntese dessa perplexidade histórica.

O município de Humaitá, por exemplo, é habitado pelas etnias Jiahui, Tenharim e Pirahã, cujas terras fazem limite com uma "Unidade de Conservação para exploração com manejo de uso múltiplo dos recursos renováveis" - área federal atualmente sob jurisdição do Ibama - que resultara da sobreposição criada pela própria União ao definir a Gleba Militar de Humaitá e, posteriormente, a Floresta Nacional Humaitá dentro de terras reclamadas pelos indígenas ${ }^{22}$. A opção dos Jiahui e Tenharim por registrar seu direito à terra construindo suas aldeias na beira da BR-230 justifica-se, por um lado, no fato de que por ela circulam bens e serviços considerados relevantes por estas populações ${ }^{23}$. Na lógica desenvolvida anteriormente, esta localização os classificaria como população rural de BRs. Mas, por outro lado, consideram aquele lugar um local sagrado profanado pelo processo de desmatamento efetuado em suas terras e, portanto, recusam-se a sair daí, onde permanecem praticando suas formas tradicionais de produção. Isto os distingue e até os antagoniza com a população rural dos entornos das BRs, que busca ampliar a fronteira agrícola na modalidade do agronegócio derrubando a floresta.

A violação dos direitos e os danos causados aos povos Tenharim e Jiahui, em decorrência da construção da BR-230, foi reconhecida pela Justiça Federal, determinando que a União e a Fundação Nacional do Índio (Funai) adotem medidas reparatórias. Segundo ação civil pública do Ministério Público Federal do Amazonas (MPF/ AM), os danos causados a esses povos podem ser classificados em ambientais (degradação do solo e dos cursos d'água, poluição atmosférica, acúmulo de lixo, redução da fauna e, principalmente, desmatamento); socioculturais (desestruturação de grupos e profanação de locais sagrados) e dano moral coletivo, em razão da omissão da União e da Funai ${ }^{23}$.

Em termos populacionais, o povo Tenharim conta atualmente com uns 700 componentes, há uns 420 Pirahã e restam apenas 97 pessoas da etnia Jiahui ${ }^{24}$. Pese ao baixo número de indígenas, conflitos étnicos ainda ocorrem no município. O último, envolvendo a morte de três habitantes não índios do município nas mãos de índios, obteve destaque na grande imprensa nacional, com a reação de parte da população não índia incen- diando as sedes da Funasa e da Funai e destruindo 13 veículos e três barcos usados no transporte de índios ${ }^{25}$.

Segundo o professor Ricardo Tavares, da Universidade do Estado do Amazonas, os conflitos que envolvem indígenas em Humaitá estariam relacionados com a chegada de ... madeireiros, grileiros e fazendeiros que estão expandindo a fronteira agrícola no sul do Amazonas, repetindo o mesmo processo acontecido no Mato Grosso e também em Rondônia ${ }^{26}$.

Vale destacar que a proposta ditatorial da integração da Amazônia Legal, por meio da ocupação estratégica de espaços geográficos que considerava "vazios", se aproxima de um mecanismo da personalidade psicótica que Jacques Lacan ${ }^{8}$ denominou Foraclusão (banimento do real na construção simbólica da realidade). Neste caso, o real (os povos indígenas) é eliminado de uma realidade oficialmente construída (o mundo simbólico) pelo governo ditatorial. Nesta perspectiva, a prática da Foraclusão em si mesma seria mais um "sintoma" que indicia a psicose coletiva que caracterizou as ditaduras cívico-militares na América Latina.

De fato, a estratégia de invisibilização das populações americanas originárias já tinha sido praticada um século antes. Militares argentinos, sob o comando do General Roca, já tinham estendido as fronteiras da "civilização" (eurocêntrica) na chamada "Campanha do Deserto". Mas o suposto deserto, era na verdade, um território habitado por várias etnias indígenas. Nesse caso, os índios vítimas de um dos maiores genocídios praticados no continente ${ }^{27}$. Nessa conjuntura, a eliminação do outro no mundo simbólico banalizou sua efetiva eliminação física do mundo real. Contudo, a teoria psicanalítica postula que o elemento foracluido (neste caso, o "outro" índio com direitos e demandas), volta em forma perturbadora (enfrentamentos, violências, conflitos) para expressar a perplexidade de uma realidade construída sem ele (pelo “eu” não índio).

Eduardo Grüner ${ }^{28}$, utiliza o conceito Foraclusão em sua análise sobre a simetria dialética entre os multiculturalismos e os multifundamentalismos. Os primeiros como herdeiros de uma teoria pós-moderna que nega a totalidade (histórica) em nome da singularidade (identidades diferentes); e os segundos como a antítese que nega as particularidades (a possibilidade da alteridade) em nome de uma totalidade (transcendente).

Grüner interpreta que a violência fundamentalista (como a observada neste conflito) é uma síntese dialética dessa contradição. Partindo deste 
ponto de vista, a violência intolerante representaria o retorno do foracluido como elemento perturbador (intolerâncias cada vez mais agressivas), que causa perplexidade na construção simbólica do imaginário dominante no capitalismo globalizado (a sociedade multicultural, o relativismo). Uma realidade que deixou de "fechar" desde os sucessos de 11 de setembro de 2001, mostrando aos teóricos pós-modernos que a história não finalizou, e que continua produzir o "real" por fora das "realidades" discursivas ${ }^{28}$.

A provocação do citado autor dá subsídios teóricos que explicam a escalada de violência intolerante em conflitos da alteridade, como os étnicos envolvendo indígenas. Em efeito, a modernidade tardia é também um projeto "totalizador" (fundamentalismo de mercado), que exibe a multiplicidade de identidades (o pretendido relativismo cultural) como simulacro do "diferente" englobado e "fechado", no projeto civilizatório do capitalismo eurocêntrico globalizado. Contudo, para poder "fechar" na dimensão do imaginário, essa "totalização" precisa foracluir as raízes profundas da luta social e, portanto, da história. Decerto, conflitos da alteridade como os enfrentamentos entre índios e não índios no sul do Amazonas, o "sintoma" da Foraclusão, expressam que é a história, e não a contingência pós-moderna, que continua a determinar os processos de subjetivação das identidades coletivas.

\section{Considerações Finais}

De acordo com a Organização Mundial da Saúde (OMS): Os determinantes sociais da saúde são as circunstâncias em que as personas nascem, crescem, vivem, trabalham e envelhecem, incluido o sistema de saúde. Essas circunstâncias são o resultado da distribuição do dinheiro, o poder e os recursos a nivel mundial, nacional e local, que depende por sua vez das politicas adoptadas ${ }^{29}$. Observe-se que nessa definição, as 'circunstâncias' que definem a saúde não são contingentes, mas o produto de um perfil distributivo que, por sua vez, está determinado pelas 'políticas aplicadas'. Tais políticas, ao se sobrepor como um dos diversos fatores determinantes, se constituiriam em 'sobredeterminantes' do processo de determinação da saúde.
Porém, sem uma teoria que apreenda a totalidade do movimento histórico de determinação social da realidade, incluída a saúde, a sobredeterminação das 'políticas aplicadas' transforma-se, automaticamente, em contingente.

Perante a pergunta: $O$ que determina, em última instância, os determinantes sociais da saúde? A resposta que se pretende dar através da abordagem socioecológica aqui apresentada é: A saúde de uma população, em sua concepção ampliada, está sobredeterminada pelos modos de produção aos quais essa população está sujeita como sujeito gerador/consumidor.

Esta sobredeterminação não é contingente, mas está ancorada a uma teoria, que postula que a forma de uma sociedade, em um certo momento do seu processo 'civilizatório', está determinada, em última instância, pela forma em que se desenvolvem suas relações sociais de produção, ou melhor dito, o modo de produção da vida material condiciona o processo de vida social, política e intelectual ${ }^{30}$, da mesma forma em que influencia na construção de identidades, do consciente e do inconsciente individual e coletivo ${ }^{28}$.

A incorporação de estudos socioecológicos em pesquisas de saúde de base territorial permitiria, por um lado, dar subsídios às análises de situação de saúde local por meio da sistematização de valiosas informações relacionadas com os processos de sobredeterminação da saúde. Estas informações são cruciais em territórios cuja matriz produtiva encontra-se em movimento de transformação, tal como é o Sul do Amazonas, um território em pleno processo de expansão das fronteiras da economia primária. E por outro lado, permitiria avançar no sentido da transdisciplinaridade, uma condição epistemológica necessária para a abordagem de uma realidade complexa e, em boa medida, ainda incerta, construída nas interfaces da produção (material, simbólica e de subjetividades); o ambiente (e seus condicionantes ecossistêmicos) e o processo saúde-doença em populações vulneradas pela inequidade, como é o campesinato amazônida. Isto é particularmente relevante nos tempos atuais, em que a agenda internacional da sustentabilidade ${ }^{31}$ e os modelos de gestão ambiental ${ }^{32}$ parecem ter-se conformado com a injusta divisão internacional do trabalho imposta pela ordem econômica vigente. 


\section{Colaboradores}

GE Schütz, MGS Mello, MAR Carvalho e VM Câmara participaram igualmente de todas as etapas de elaboração do artigo.

\section{Agradecimentos}

Ao Instituto Nacional de Pesquisa Translacional em Saúde e Ambiente na Região Amazônica (INPeTAm) pelo financiamento desta pesquisa.

\section{Referências}

1. Marx K. El capital. México: Siglo XXI; 1981. (Tomo III. Vol. 8)

2. Foladori G. El metabolismo con la naturaleza. Marxismo ecológico. 2009 [página na internet]. [acessado 2014 abr 21]. Disponível em: http://marxismoecologico.blogspot.com.br/2009/12/el-metabolismo-con-lanaturaleza.html

3. Mészáros I. Para além do Capital. São Paulo: Boitempo; 2002.

4. Clark B, Foster JB. A dialética do metabolismo social e ecológico: Marx, Mészáros e os limites absolutos do capital. In: Jinkings I, Nobile R, organizadores. István Mészáros e os desafios do tempo histórico. São Paulo: Boitempo; 2011. p.117-128.

5. Angrosino M. Etnografia e Observação Participante. Porto Alegre: Artmed; 2009

6. Santos M. Espaço e Sociedade. Petrópolis: Vozes; 1979.

7. Weber M. Ensaios de sociologia. Rio de Janeiro: LTC Editora; 1979.

8. Lacan J. O Seminário. Livro 3: As psicoses. Rio de Janeiro: Jorge Zahar; 1985.

9. Machado de Lima A. Descobrimento e Colonização do Vale do Rio Madeira. Gente de Opinião [página na internet]. 2008 [acessado 2014 abr 21]. Disponível em: http://www.gentedeopiniao.com.br/lerConteudo. php?news $=32395$

10. Correa MT. Ribeirinhos do Madeira. Primeira Versão 2003. Ano II; 95(6). [página na internet]. [acessado 2014 abr 21]. Disponível em: http//www.primeiraversao.unir. br/atigos_pdf/numero095Terezinha.pdf

11. Fechine EFG. Condições de vida e trabalho das mulheres ribeirinhas do rio Madeira. Porto Velho: Fundação UFRO; 2008. [página na internet]. [acessado 2014 abr 21]. Disponível em: http://itaporanga.net/genero/1/GT 10/08.pdf

12. Furtado LG. Amazônia: Desenvolvimento, Sóciodiversidade e Qualidade de Vida. Belém: UFPA; 1997.

13. Agência Nacional de Transportes Aquaviários (ANTAq). Transporte de Cargas na Hidrovia do Rio Madeira. Brasília: Antaq; 2010. [página na internet]. [acessado 2014 abr 21]. Disponível em: http://www.antaq.gov.br/ Portal/pdf/HidroviaDoMadeiraTransportedeCargas. pdf

14. Portella F. A Contribuição do Setor de Serviços ao Produto Interno Brasileiro [monografia]. São Paulo: FEFAP; 2008.

15. Malta V. Humaitá-AM Ultrapassa os 44.000 mil Habitantes. Jornal Humaitá Notícias; 2010. [página na internet]. [acessado 2014 abr 21]. Disponível em: http:// humaitanoticias.com.br/Noticia.asp?ID $=1529$

16. Furtado A. População rural do AM encolheu em dez anos. A Crítica; 2011. [página na internet]. [acessado 2014 abr 21]. Disponível em: http://www2.acritica .com/noticias/ Populacao-rural-AM-encolheu_0_469753079.html

17. Instituto Brasileiro de Geografia e Estatística (IBGE). Estimativas da População Residente nos Municípios Brasileiros com Data de Referência em $1^{\circ}$ de Julho de 2013. Diretoria de Pesquisas - DPE. [página na internet]. [acessado 2014 abr 21]. Disponível em: ftp://ftp.ibge. gov.br/Estimativas_de_Populacao/Estimativas_2013/ estimativa_2013_dou.pdf 
18. Scherer E. Modos de vida ribeirinha na Amazônia. In: XII Congresso Brasileiro de Sociologia; 2005; Belo Horizonte. [página na internet]. [acessado $2014 \mathrm{abr}$ 21]. Disponível em: http://www.sbsociologia.com.br/ portal/index.php?option $=$ com_docman\&task $=$ doc download\&gid $=643 \&$ Itemid $=171$

19. Brasil. Decreto no 5.051 , de 19 de abril de 2004. Promulga a Convenção no 169 da Organização Internacional do Trabalho - OIT sobre Povos Indígenas e Tribais. Diário Oficial da União 2004; 24 abr.

20. Brasil. Saúde da Família. Política Nacional de Atenção à Saúde dos Povos Indígenas. Departamento de Atenção Básica; s/d. [página na internet]. [acessado $2014 \mathrm{abr}$ 21]. Disponível em: http://www.dab.saude.gov.br/saude_indigena.php

21. Brasil. Decreto no 7.747 , de 5 de junho de 2012. Institui a Política Nacional de Gestão Territorial e Ambiental de Terras Indígenas - PNGATI, e dá outras providências. Diário Oficial da União 2012; 6 jun.

22. Paggion EA. Povos Indígenas no Brasil: Jiahui. Instituto Sócio Ambiental (ISA); 2002 [página na internet]. [acessado 2014 abr 21]. Disponível em: http://pib. socioambiental.org/pt/povo/jiahui/1328

23. Amigos da Terra - Amazônia Brasileira. MPF/AM obtém reparação a povos indígenas em razão da rodovia Transamazônica. Amazônia; 2014. [página na internet]. [acessado 2014 abr 21]. Disponível em: http://amazonia. org.br/2014/02/mpfam-obtem-reparacao-a-povosindigenas-em-razao-da-rodovia-transamazonica/

24. Instituto Sócio Ambiental (ISA). Quadro Geral dos Povos; s/d. [página na internet]. [acessado em $2014 \mathrm{abr}$ 21]. Disponível em: http://pib.socioambiental.org/ $\mathrm{pt} / \mathrm{c}$ /quadro-geral

25. Barbosa J. Moradores ateiam fogo em sede da FUNAI e entram em conflito com polícia no Amazonas. Folha de São Paulo 2013; 26 dez. [página na internet]. [acessado em 2014 abr 21]. Disponível em: http://www1. folha.uol.com.br/poder/2013/12/1390289-moradoresateiam-fogo-em-sede-da-funai-e-entram-em-conflitocom-policia-no-amazonas.shtml
26. Diário da Amazônia. Corpos de três homens estão no IML. Diário da Amazônia 2014; 5 fev. [página na internet]. [acessado 2014 abr 21]. Disponível em: http://www.diariodaamazonia.com.br/corpos-de-treshomens-estao-no-iml/

27. Diamond J. O terceiro Chimpanzé: a evolução e o futuro do ser humano. Rio de Janeiro: Record; 2010.

28. Grüner E. El fin de las pequeñas historias: De los estudios culturales al retorno (imposible) de lo trágico. Buenos Aires: Paidós; 2005.

29. Organización Mundial de la Salud (OMS). Temas de Salud: Determinantes Sociales de la salud; s/d. [página na internet]. [acessado em 2014 abr 21]. Disponível em: http://www.who.int/topics/social_determinants/es/

30. Marx K. Contribuição à Crítica da Economia Política. São Paulo: Expressão Popular; 2008.

31. Schütz GE, Tambellini AT, Asmus CIRF, Meyer A, Câmara VM. A agenda da sustentabilidade global e sua pauta oficial: uma análise crítica na perspectiva da Saúde Coletiva. Cien Saúde Colet 2012; 17(6):1407-1418.

32. Porto MFS, Schütz GE. Gestão ambiental e democracia: análise crítica, cenários e desafios. Cien Saúde Colet 2012; 17(6):1447-1456.

Artigo apresentado em 07/07/2014

Aprovado em 08/07/2014

Versão final apresentada em 09/07/2014 